\title{
Bio-based Aromatic Amines from Lignin-Derived Monomers
}

\author{
Enguerrand Blondiaux, ${ }^{\dagger}$ Jeroen Bomon, ${ }^{\dagger} \odot$ Michał Smolen, $^{\dagger}$ Nadya Kaval, ${ }^{\dagger}$ Filip Lemière, ${ }^{\dagger}$ \\ Sergey Sergeyev, ${ }^{\dagger}$ Ludo Diels, ${ }^{\dagger,+}$ Bert Sels, ${ }^{\S}{ }^{\circledR}$ and Bert U. W. Maes ${ }^{*}, \dagger(0)$ \\ ${ }^{\dagger}$ Department of Chemistry, University of Antwerp, Groenenborgerlaan 171, B-2020 Antwerp, Belgium \\ ${ }^{\ddagger}$ Flemish Institute for Technological Research-VITO, Boeretang 200, B-2400 Mol, Belgium \\ ${ }^{\S}$ Center for Surface Chemistry and Catalysis, KU Leuven, Celestijnenlaan 200F, B-3001 Leuven, Belgium
}

\begin{abstract}
A new approach to synthesize valuable 3,4- Lignin depolymerization dialkoxyanilines and alkyl propionates from lignin-derived 4propylguaiacol and -catechol with overall isolated yields up to $65 \%$ has been described. The strategy is based on the introduction of nitrogen via a Beckmann rearrangement. Amino introduction therefore coincides with a $C$-defunctionalization reaction; overall a replacement of the propyl chain by an amino group is obtained. The process only requires cheap bulk chemicals as reagents/reactants and does not involve column chromatography to purify the reaction products. Furthermore, all carbon atoms from the biorenewable lignin-derived monomers are transformed into valuable compounds.

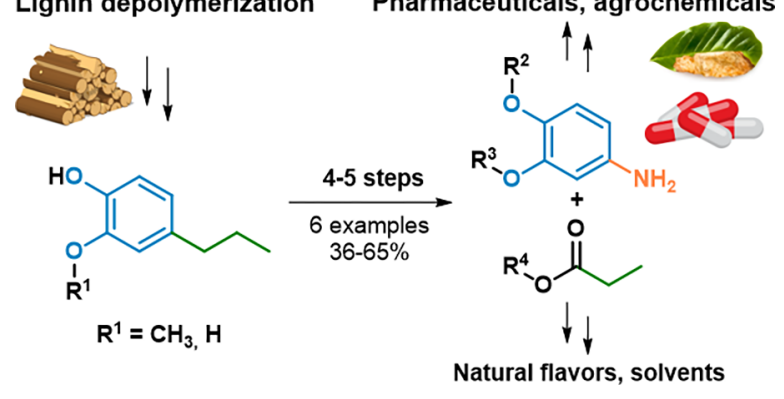
Greenness was assessed by performing a Green Metrics analysis on two dialkoxyanilines. A comparison was made with literature routes for these compounds starting from a petrochemical substrate.
\end{abstract}

KEYWORDS: Anilines, Biorenewable chemicals, Benzylic oxidation, Beckmann rearrangement, Green Metrics, Bioaromatics

\section{INTRODUCTION}

Aromatic amines are key building blocks in industry. Aniline, the parent molecule of this family, is used to manufacture more than 300 products. $^{1}$ About $65 \%$ of the worldwide aniline production, estimated to 4-7 Mt/year, is used to produce methylene diphenylene isocyanate (MDI), the most widely used isocyanate for polyurethane synthesis. ${ }^{1}$ Substituted anilines find many applications in the production of more complex molecules such as azo dyes, pigments, fertilizers, pesticides, and pharmaceuticals. ${ }^{2}$

Aniline is industrially mainly produced from benzene via its direct nitration in liquid phase using nitric and sulfuric acid, followed by catalytic hydrogenation of nitrobenzene generally using palladium or copper on activated carbon or an oxidic support as catalyst. ${ }^{1,3-5}$ Most substituted anilines, such as chloroanilines, toluidines, anisidines, and xylidines, are manufactured following the same process by nitration and reduction of the corresponding substituted benzene. ${ }^{1}$ A second minor route involves nucleophilic substitution $\left(S_{N} A r\right)$ of a halogen, hydroxyl, alkoxy, or hydroxysulfonyl group by an amino group using ammonia. ${ }^{2}$

Although nitration of substituted benzenes with nitric acid is a common industrial process, it is not hazard-free, and serious accidents have been reported. ${ }^{6}$ Nitric acid is not only very corrosive but also toxic and a strong oxidant. Because of its high oxidizing power, nitric acid reacts violently with various organic compounds. The nitrated organic compound itself, however, can also be shock sensitive or thermally instable and is therefore not an ideal intermediate for a sustainable aromatic amine synthesis. ${ }^{6}$ Approaches which avoid nitration to introduce nitrogen and start from a feedstock that already possesses arene substituents, such as a biorenewable resource, therefore are attractive new strategies to produce aromatic amines.

Biorenewable resources are an interesting source of arenes. In 2016, Caillol et al. reviewed the various routes for synthesis of bio-based amines from available renewable feedstock. ${ }^{7}$ Remarkably, while aliphatic amines have been extensively studied, only a few examples are hitherto reported for aromatic amine synthesis. These are all based on cardanol, extracted from cashew nut shell liquid, and involve $S_{\mathrm{E}}$ Ar reactions. ${ }^{8-11}$ Cardanol derivatives are nitrated with nitric acid or undergo diazo coupling with the diazonium salt of sulfanilic acid. Reduction toward amine is performed in the presence of a Pd/ $\mathrm{C}$ catalyst with hydrazine for the nitro and with sodium dithionite for the diazo group. Hence, the safety concerns related to the use of nitric acid are not eliminated in this approach.

Lignin is considered as the largest source of biorenewable aromatics and therefore an interesting feedstock for producing bioaromatic chemicals. ${ }^{12-14}$ Many strategies for depolymerization of lignin have been reported, ${ }^{15-24}$ producing mixtures of 
para-substituted guaiacols and syringols. However, only a few examples gave a discrete set of chemicals which would be required as a feedstock for transformation into industrially relevant chemicals. Thus, reductive cleavage of lignin or wood with external or in situ generated $\mathrm{H}_{2}$ using $\mathrm{Ni} / \mathrm{C}, \mathrm{Pd} / \mathrm{C}$, and $\mathrm{Ru} / \mathrm{C}$ as catalysts, developed by various groups, produced mixtures of mainly 4-propylguaiacol (1a) and 4-propylsyringol, with a total monomer yield up to $50 \%$ (carbon yield) at a temperature of $250{ }^{\circ} \mathrm{C}$ and a pressure of $30 \mathrm{bar} \mathrm{H}_{2}$ gas when using birch wood. ${ }^{25-28}$ Despite the lower total monomer yield (20\%), treatment of pine wood under the same conditions delivered a lignin oil consisting for more than $80 \%$ 1a in an amount corresponding to $12 \mathrm{wt} \%$ of the original lignin content. $^{29}$ Other examples producing 4-propylcatechol (1b) and 5-(3-hydroxypropyl)pyrogallol ${ }^{30}$ or 3-hydroxy-1-(4-hydroxy-3,5-dimethoxyphenyl)propan-1-one ${ }^{31}$ as predominant products were also reported (Figure 1).<smiles>CCCc1ccc(O)c(OC)c1</smiles><smiles>CCCc1ccc(O)c(O)c1</smiles>

Figure 1. Lignin-derived monomers.

Valorization of those phenolic monomers by transformation in new or known (drop-in) chemicals is very important in the context of fossil resource replacement. 4-Propylguaiacol and 4propylcatechol have for example been used to make new biobased epoxy resins, ${ }^{32,33}$ bisphenol analogues, ${ }^{34,35}$ and cyclohexanone-based polymer building blocks featuring an additional propyl substituent. ${ }^{36}$ Transformations which remove the propyl chain and concomitantly introduce a substituent on the arene, although not studied yet, would be interesting to further broaden the product scope of these phenolic monomers.
Surprisingly there is, to the best of our knowledge, also no reported example of aromatic amine synthesis from ligninderived monomers. ${ }^{37}$ Combining these aspects, we reasoned that 4-propylguaiacol and 4-propylcatechol could serve as platform chemicals to synthesize 3,4-dialkoxy-substituted anilines, by replacement of the propyl chain by an amino group. 3,4-Dialkoxyanilines find application in the preparation of 4-chloro-6,7-dialkoxyquinazoline (A) and 2,4-dichloro-6,7dialkoxyquinazoline (B) (Figure 2), ${ }^{38,39}$ intermediates in the preparation of widely used anticancer drugs such as Prazosin, Alfuzosin, Doxazosin, Terazosin, Gefitinib, and Erlotinib (Figure 2). ${ }^{40-47}$ 3,4-Dimethoxyaniline is a chemical used in dyes synthesis, with a price of $10-16 € / \mathrm{kg}(1.5-2.5 € / \mathrm{mol}){ }^{48}$ and 3,4-diethoxyaniline finds a niche application in the preparation of Diethofencarb, a fungicide used to prevent Botrytis. $^{49}$

The proposed strategy to access 3,4-dialkoxyanilines from 4propylguaiacol (1a) is presented in Figure 3. It consists of an alkylation of the $-\mathrm{OH}$ group followed by a benzylic oxidation, a Beckmann rearrangement, and finally an amide alcoholysis. Beckmann rearrangement on the propiophenones 3, relying on cheap salts of hydroxylamine, is the core reaction of the strategy and a safe way to introduce nitrogen onto an aromatic ring. ${ }^{50}$ In the last step of the sequence, besides 3,4dialkoxyanilines 5, a propionate ester byproduct is obtained. These esters are valuable compounds as they are industrially used as solvents and as flavors. ${ }^{51}$ Interestingly, our strategy therefore allows one to concomitantly valorize the byproduct into natural flavors and to transform all biorenewable carbon into industrially valuable products, and therefore to maximize the utilization of the functionality given by Nature. In our approach to access dialkoxyanilines we aim to maximize the
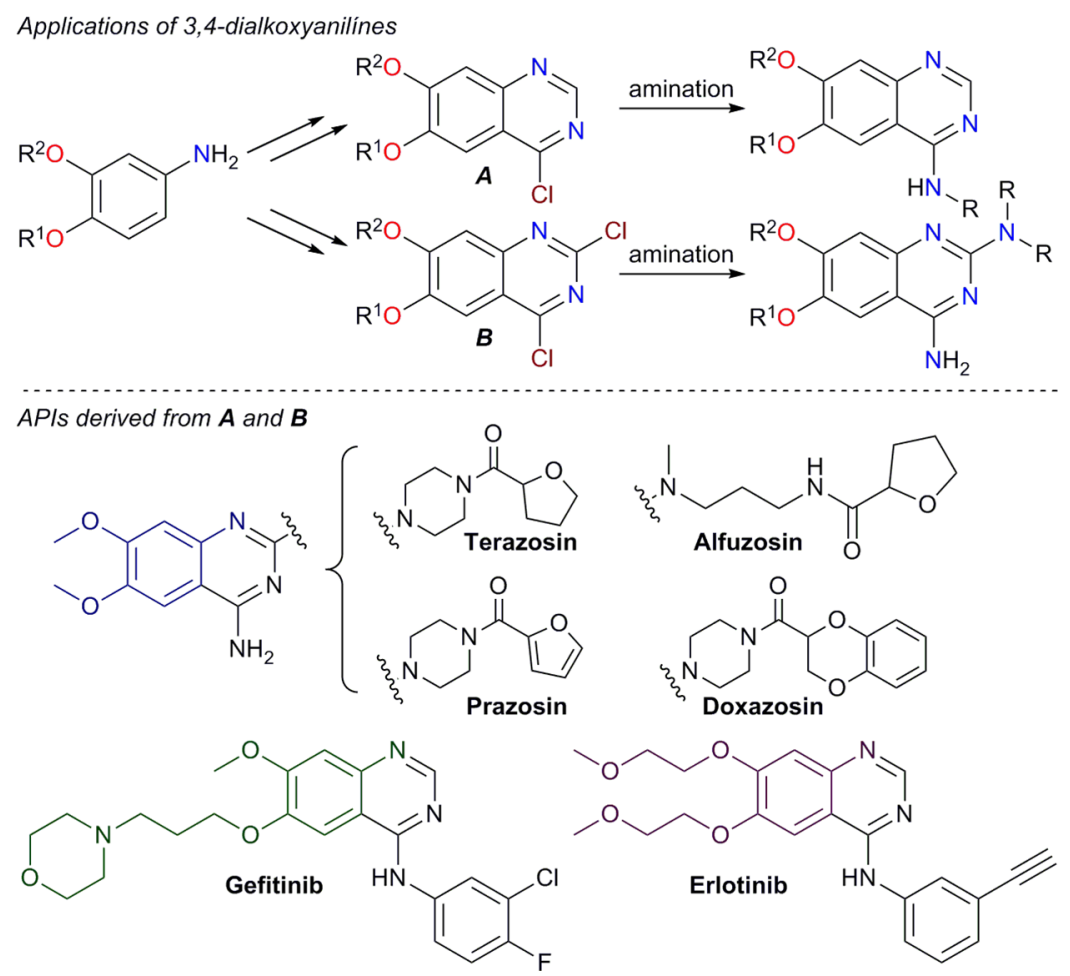

Figure 2. Synthesis of 4-chloro-6,7-dialkoxyquinazoline (A) and 2,4-dichloro-6,7-dialkoxyquinazoline (B) from 3,4-dialkoxyanilines, and APIs derived from them. 


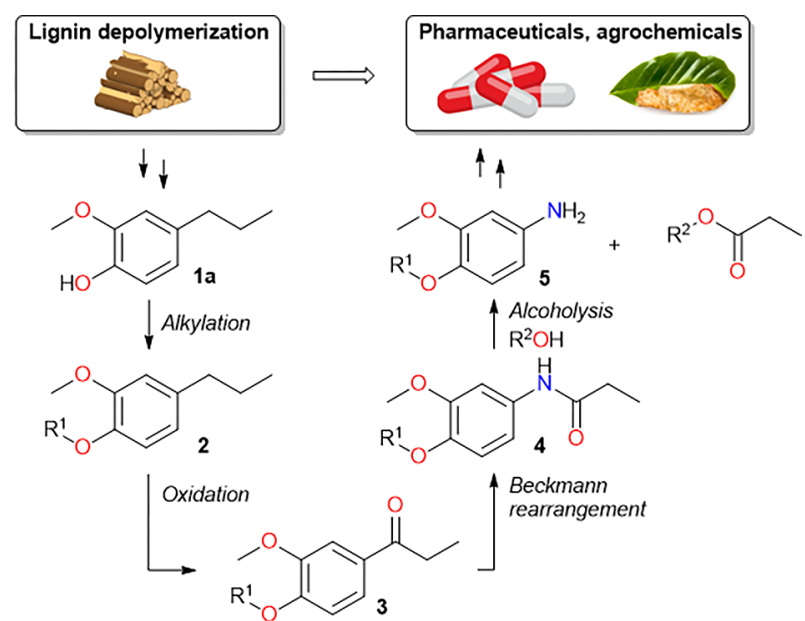

Figure 3. Strategy for 4-alkoxy-3-methoxyaniline (5) synthesis from biorenewable 4-propylguaiacol (1a).

use of green and industrially acceptable chemicals (considering price) as reactants, reagents, and solvents.

\section{RESULTS AND DISCUSSION}

Route Development. As a proof of concept to explore the new strategy, the synthesis of 3,4-dimethoxyaniline (5a) from 4-propylguaiacol (1a) was chosen given its current industrial use. $^{48}$

Step 1: Methylation of 4-Propylguaiacol (1a). 1,2Dimethoxy-4-propylbenzene (2a) was prepared from 1a using dimethyl carbonate (DMC) as the methylating agent and solvent in the presence of a catalytic amount of base, i.e., 1 mol \% $\mathrm{K}_{2} \mathrm{CO}_{3} .{ }^{52-54} \mathrm{~A}$ quantitative yield was obtained after heating at $200{ }^{\circ} \mathrm{C}$ for $24 \mathrm{~h}$ in a sealed vessel (see the Supporting Information (SI) for optimizations). DMC is recognized as a green, biodegradable, nontoxic, and mild methylation agent. It is therefore more suitable than other classical methylating agents, such as iodomethane and dimethyl sulfate (Figure 4).

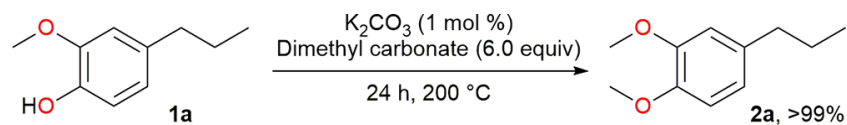

Figure 4. Methylation of 1a using dimethyl carbonate.

Step 2: Oxidation of 1,2-Dimethoxy-4-propylbenzene (2a). Benzylic oxidation of $2 \mathrm{a}$ has been reported using 2.2 equiv of 2,3-dichloro-5,6-dicyano-1,4-benzoquinone (DDQ) in a mixture of 1,4-dioxane $/ \mathrm{H}_{2} \mathrm{O}$ at reflux, yielding $70 \% 3 \mathrm{a}^{55-58}$ Photoredox catalysis based on dicyanonapthalene (DCN) under air in $\mathrm{CH}_{3} \mathrm{CN} / \mathrm{H}_{2} \mathrm{O}$ at room temperature gave $78 \%$ 3a. ${ }^{59}$ However, both DDQ and the photoredox catalyst are too expensive to allow scaleup of this benzylic oxidation. To synthesize $1 \mathrm{~mol}$ of $3 \mathrm{a}$, about $47 €$ of DDQ and $44 €$ of DCN oxidant cost would be required (Figure 5).

We therefore searched for conditions based on a cheaper oxidant commonly used in industry. $t \mathrm{BuOOH}$ was the first oxidant considered. It is commonly used in various oxidation reactions and finds industrial application in the production of propylene oxide. ${ }^{60}$ However, 3 equiv of $t \mathrm{BuOOH}$ in pyridine catalyzed by $\mathrm{FeCl}_{3} \cdot 6 \mathrm{H}_{2} \mathrm{O}$ gave only $12 \%$ 1- $(3,4$ dimethoxyphenyl)propan-1-one (3a) after $64 \mathrm{~h}$ at $85{ }^{\circ} \mathrm{C}$. ${ }^{61}$
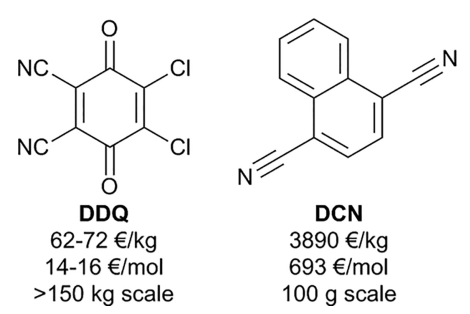

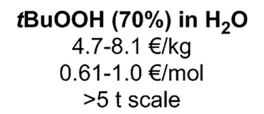

$\mathbf{X}_{2} \mathbf{S}_{2} \mathrm{O}_{8}$
$\mathrm{X}=\mathrm{NH}_{4} \mathrm{Na}, \mathrm{K}$
$0.70-2.0 € / \mathrm{kg}$
$0.16-0.54 € / \mathrm{mol}$

$>15$ t scale

$1.7-2.0 € / \mathrm{kg}$

$0.52-0.61 € / \mathrm{mol}$

$>15 \mathrm{t}$ scale
Figure 5. Prices of bulk and fine chemical oxidants. ${ }^{48}$

We then turned our attention to salts of peroxydisulfate $\left(\mathrm{K}^{+}\right.$, $\mathrm{Na}^{+}$, and $\left.\mathrm{NH}_{4}^{+}\right)$. These are cheap oxidants $(0.16-0.54 € / \mathrm{mol})$ produced in about 160 kton quantities annually. ${ }^{48}$ In industry, they are mainly used to initiate polymerization and to etch metal. ${ }^{62}$ Although they are common reagents, they have not often been studied as oxidants for benzylic oxidation. Such oxidations have been observed as side reactions ${ }^{63,64}$ or have been applied on specific substrates under acidic conditions $\left(\mathrm{H}_{2} \mathrm{SO}_{4}\right){ }^{65}$ Nevertheless, those results suggest that peroxydisulfate salts could promote benzylic oxidation in a general way. The highest yield was obtained when combining 2.4 equiv of $\mathrm{Na}_{2} \mathrm{~S}_{2} \mathrm{O}_{8}$ with 1.0 equiv of $\mathrm{NaOAc}$ in a mixture of $\mathrm{CH}_{3} \mathrm{CN}$ / $\mathrm{H}_{2} \mathrm{O}$ (Figure 6; see the Supporting Information for optimization).

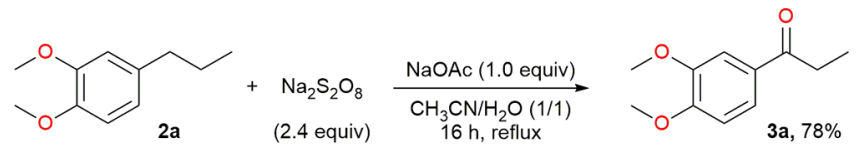

Figure 6. Oxidation of $2 \mathrm{a}$ into $3 \mathrm{a}$.

Step 3: Beckmann Rearrangement of 1-(3,4Dimethoxyphenyl)propan-1-one (3a). Ketone 3a was transformed into $N$-(3,4-dimethoxyphenyl)propionamide (4a) by Beckmann rearrangement of the in situ formed oxime. With hydroxylamine hydrochloride in formic acid at $80{ }^{\circ} \mathrm{C}$, 3a was smoothly transformed into the expected amide $4 \mathbf{a}$ (74\% yield) (Figure 7). Noteworthy, no undesired regioisomeric amide $4 \mathbf{a}^{\prime}$ was obtained. Migration was therefore fully regioselective toward veratrole.

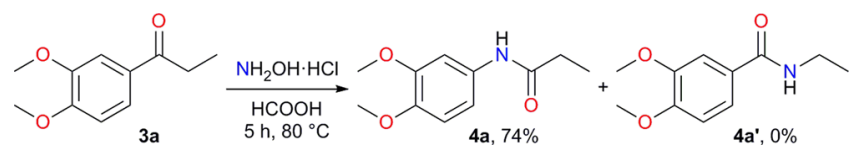

Figure 7. Beckmann rearrangement of $\mathbf{3 a}$.

Step 4: Amide Cleavage of N-(3,4-Dimethoxyphenyl)propionamide (4a). Amide 4a could be cleaved under acidic conditions using a solution of $\mathrm{HCl}$ in ethanol. 3,4Dimethoxyaniline (5a) and ethyl propionate were obtained in a nearly quantitative yield by heating at $70{ }^{\circ} \mathrm{C}$ in ethanol followed by a basic workup (Figure 8). ${ }^{86,67}$

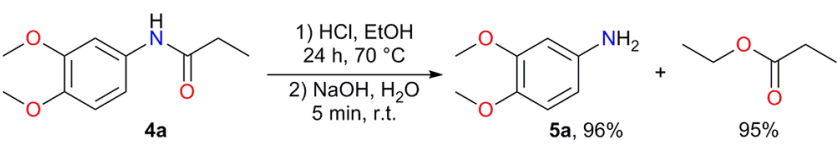

Figure 8. Alcoholysis of $\mathbf{4 a}$. 
Transformation of $1 \mathrm{a}$ into $5 \mathrm{a}$ without Intermediate Purification. In order to test the robustness of this four-step procedure and to pave the way to an industrial process, the synthesis was performed without any purification after each individual synthetic step, the crude mixture being directly engaged in a following transformation. Workup only required filtrations and liquid-liquid extractions. After the alcoholysis step, 5a was obtained as a hydrochloride salt together with alkyl propionate. Taking advantage of the salt formation, the reaction mixture was concentrated under reduced pressure in order to afford an alcoholic solution of alkyl propionate as distillate. The crude product remaining was then diluted with $\mathrm{H}_{2} \mathrm{O}$ and extracted with an organic solvent to remove the organic impurities, whereas the aqueous layer contained 5a. $\mathrm{HCl}$. Basification of this aqueous layer with an aqueous solution of $\mathrm{NaOH}$ and extraction with an organic solvent gave pure 3,4-dimethoxyaniline in 52\% yield upon solvent removal (Figure 9).
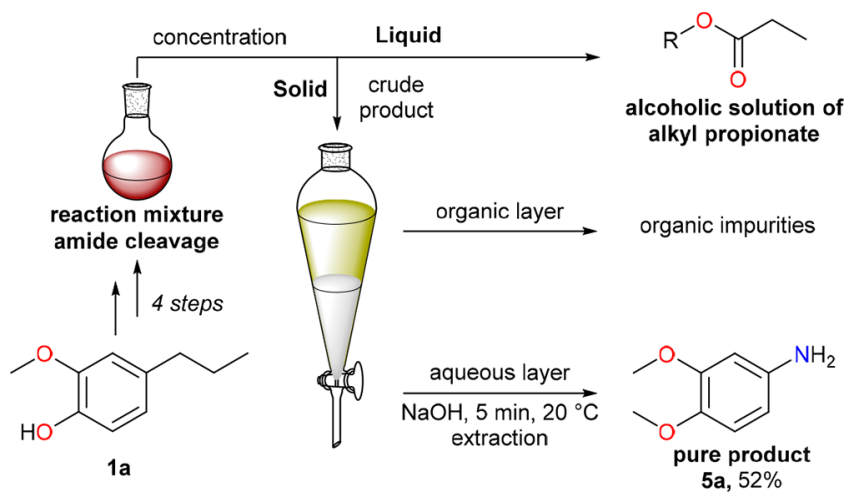

Figure 9. Workup procedure for the purification of crude 3,4dimethoxyaniline (5a) obtained from 1a without intermediate isolation.

4-Alkoxy-3-methoxyanilines (5) from 4-Propylguaiacol (1a). O-Ethylated derivative $\mathbf{2 b}$ was obtained by using DEC (diethyl carbonate), since ethylation using DEC was found to be greener than the classical approach using EtI (see Supporting Information for Green Metrics). The O-Ethoxyethyl alkylated 4-propylguaiacol derivative $2 \mathrm{c}$ was synthesized from 1a by using an alkyl bromide reactant instead of a carbonate for the alkylation reaction (step 1). These $O$ alkylated propylguaiacols delivered the corresponding anilines $\mathbf{5 b}$ and $\mathbf{5 c}$ with isolated yields ranging from 61 to $65 \%$ (Figure 10) after 4 steps.

Unfortunately, aniline 5d, precursor of the Gefitinib synthesis, could not be prepared following this procedure. Oxidation of $2 \mathbf{d}$ by $\mathrm{Na}_{2} \mathrm{~S}_{2} \mathrm{O}_{8} / \mathrm{NaOAc}$ into $3 \mathbf{d}$ proved unsuccessful (Figure 11). Compound 1a was therefore transformed into $2 \mathrm{e}$ using 1-bromo-3-chloropropane as the alkylating reactant. Fortunately, oxidation of $2 \mathrm{e}$ into $3 \mathrm{e}$ worked smoothly, and subsequent Beckmann rearrangement gave amide 4e. Substitution of the chlorine in $4 \mathbf{e}$ by morpholine in the presence of $\mathrm{K}_{2} \mathrm{CO}_{3}$ in $\mathrm{CH}_{3} \mathrm{CN}$ under reflux finally gave amide $\mathbf{4 f}$, which was then transformed into the desired aniline 5d by alcoholysis using $\mathrm{HCl}$ in $\mathrm{EtOH}$ at $70{ }^{\circ} \mathrm{C}$. This provided 5d with an overall yield of $36 \%$ after five steps (Figure 11).

The synthesis of Gefitinib from $\mathbf{5} \mathbf{d}$ has been described with a yield of $60 \%{ }^{38}$ its synthesis from 4-propylguaiacol (1a) results then in an overall yield of $22 \%$ in 10 steps (Figure 12).

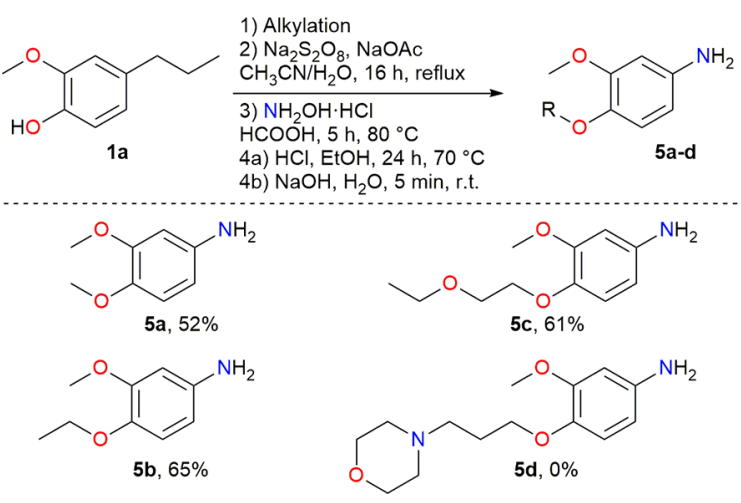

Figure 10. Transformation of 1a into 3,4-dialkoxyanilines 5 without intermediate isolation. Reaction conditions: (1) 1a $(2.80 \mathrm{mmol})$, DMC (or DEC) (6 equiv), and $\mathrm{K}_{2} \mathrm{CO}_{3}$ or $\mathrm{Cs}_{2} \mathrm{CO}_{3}$ (0.01 equiv) for preparation of $\mathbf{5 a}$ and $\mathbf{5 b}$, respectively; 1a, 1-bromo-2-ethoxyethane or 4-(3-chloropropyl)morpholine (1.5 equiv) with $\mathrm{K}_{2} \mathrm{CO}_{3}$ (2.0 equiv) in acetone or ethanol $(10 \mathrm{~mL})$ for preparation of $\mathbf{5 c}$ and $\mathbf{5 d}$, respectively. (2) Crude 2 (around $2.80 \mathrm{mmol}$ ), $\mathrm{Na}_{2} \mathrm{~S}_{2} \mathrm{O}_{8}$ (2.4 equiv), $\mathrm{NaOAc}(1.0$ equiv) in $\mathrm{CH}_{3} \mathrm{CN} / \mathrm{H}_{2} \mathrm{O}(50 \mathrm{~mL}, 1 / 1$ mixture). (3) Crude 3 (around $1.82 \mathrm{mmol}$ ), $\mathrm{NH}_{2} \mathrm{OH} \cdot \mathrm{HCl}$ (2.0 equiv) in $\mathrm{HCOOH}(5 \mathrm{~mL})$. (4a) Crude 4 (around $1.55 \mathrm{mmol}$ ) in $1.25 \mathrm{M} \mathrm{HCl}$ solution in $\mathrm{EtOH}(2.0$ equiv). (4b) Crude $5 \cdot \mathrm{HCl}, \mathrm{NaOH}(1.5$ equiv). Overall yields of the isolated product.

Similar to the synthesis starting from 1a, 4-propylcatechol (1b) was used in the same procedure (Figure 9). In this case a double $\mathrm{O}$-alkylation occurs giving access to dialkoxyanilines. A first example is 3,4-bis(methoxyethoxy)aniline (5g), a precursor for Erlotinib, which was prepared using methoxyethyl bromide with an overall yield of $47 \%$ (Figure 13).

A second example is 3,4-diethoxyaniline (5h), which was obtained with a similar yield of 54\% (Figure 13). Fungicide diethofencarb (6) was subsequently prepared from 5 h by reaction with isopropyl chloroformate, with a yield of $89 \%$ in toluene following a literature procedure ${ }^{68}$ (Figure 14). Diethofencarb can therefore be synthesized in five steps from $1 \mathrm{~b}$ with an overall yield of $48 \%$.

2-Bromo-4,5-dimethoxyaniline (7) from 4-Propylguaiacol (1a). Having this simple procedure to access 3,4dialkoxyanilines in hand, we decided to combine it with an $S_{E} A r$ reaction to show that even more substituted anilines can be easily accessed. The synthesis of 2-bromo-4,5-dimethoxyaniline (7) from 1a was selected as a model case as we recently developed a new methodology to access 6,7dimethoxy-2,4-dichloroquinazoline (12) from 7 by a $\mathrm{Pd}$ catalyzed three-component reaction of 2-bromoanilines, $\mathrm{CO}_{2}$, and isocyanides which form 11 (Figure 15). ${ }^{39}$

In literature, synthesis of 7 from 3,4-dimethoxyaniline (5a) has been described using tetrabutylammonium tribromide in $\mathrm{CH}_{2} \mathrm{Cl}_{2} / \mathrm{MeOH}$, but it gave only $30 \%$ isolated yield after column chromatography. ${ }^{40}$ In order to efficiently prepare 7 from 1a, the bromination therefore needs to be performed in an earlier step. Treating $\mathbf{2 a}$ with an aqueous $\mathrm{HBr}$ solution and DMSO in EtOAc ${ }^{69}$ gave $85 \% 8$ (Figure 16, reaction A), but its oxidation using $\mathrm{Na}_{2} \mathrm{~S}_{2} \mathrm{O}_{8} / \mathrm{NaOAc}$ gave only $34 \% 9$ (Figure 16, reaction $\mathrm{B}$; see the Supporting Information). It turned out that treatment of 3a with $\mathrm{HBr}$ and DMSO in EtOAc led to an undesired bromination in the $\alpha$-position of the ketone instead of a $S_{E} A r$ (Figure 16, reaction C, and Supporting Information). Finally, bromination of amide $4 \mathrm{a}$ using the same system turned 

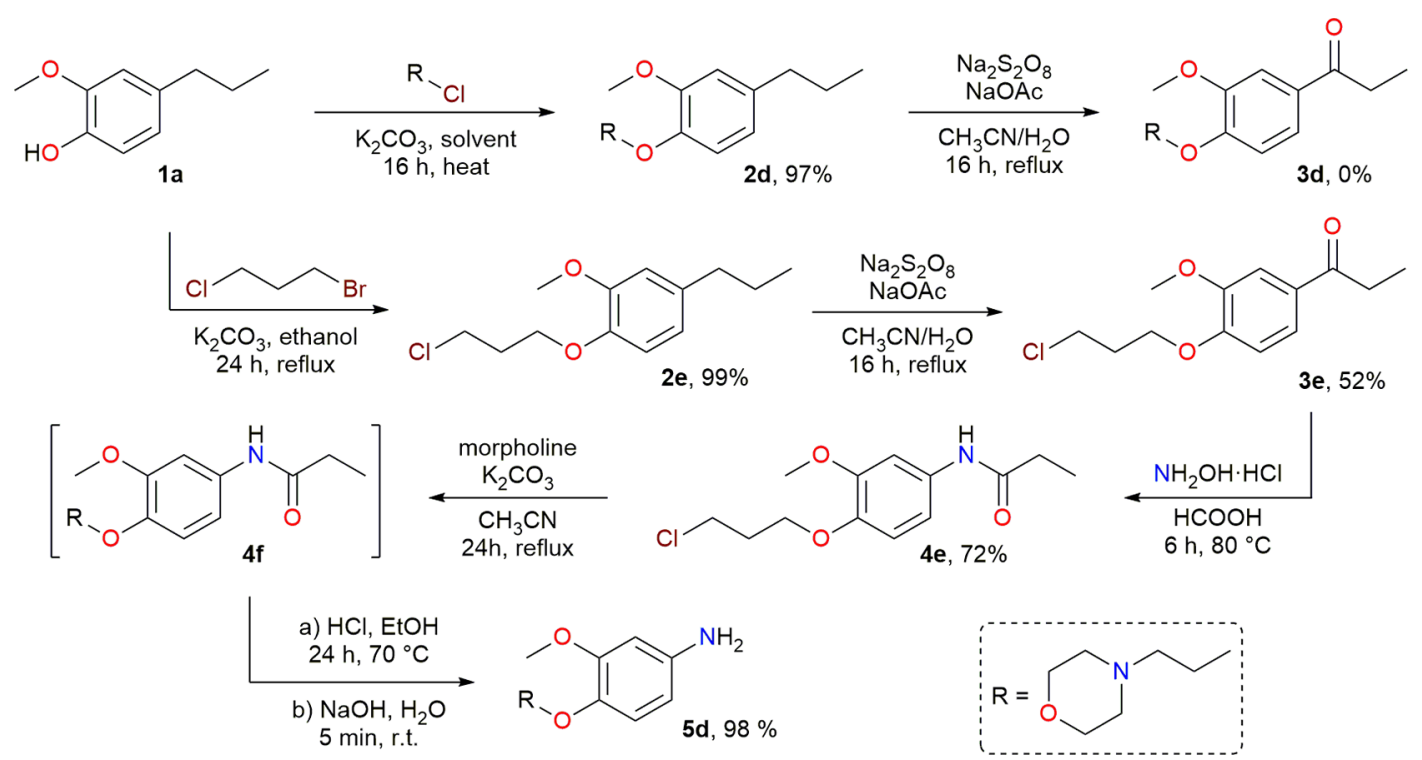

Figure 11. Preparation of aniline 5d from 1a.

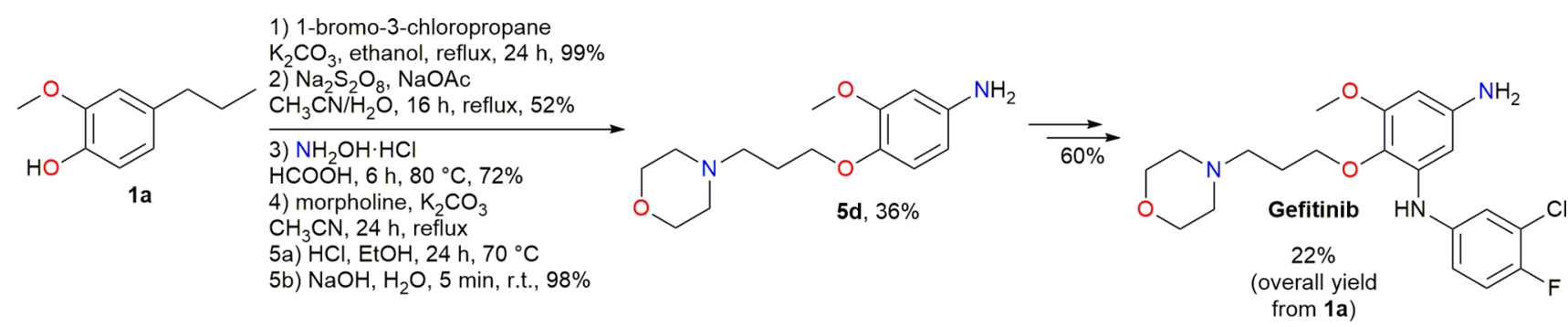

Figure 12. Preparation of Gefitinib from 1a. ${ }^{38}$

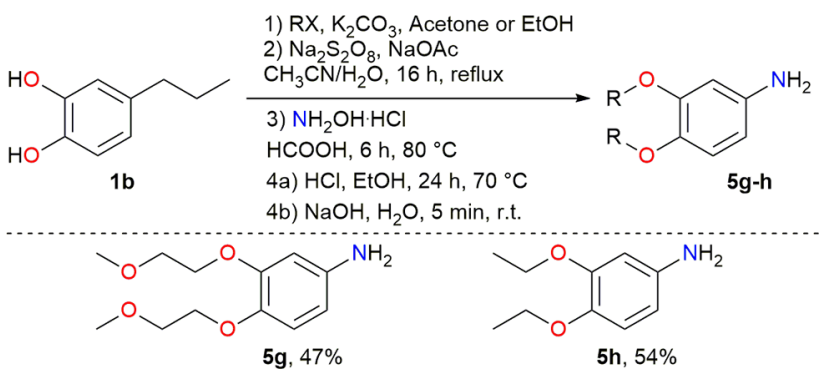

Figure 13. Transformation of $\mathbf{1 b}$ into 3,4-dialkoxyaniline $\mathbf{5}$ without intermediate isolation. Reaction conditions: (1) 1-Bromo-2-methoxyethane (3.0 equiv) or iodoethane (4.0 equiv) with $\mathrm{K}_{2} \mathrm{CO}_{3}$ (2.0-4.0 equiv) in acetone $(10 \mathrm{~mL})$ for preparation of $\mathbf{5 g}$ and in ethanol $(10$ $\mathrm{mL}$ ) for preparation of $5 \mathbf{h}$. (2) Crude $2(2.80 \mathrm{mmol}), \mathrm{Na}_{2} \mathrm{~S}_{2} \mathrm{O}_{8}(2.4$ equiv), $\mathrm{NaOAc}$ (1.0 equiv) in $\mathrm{CH}_{3} \mathrm{CN} / \mathrm{H}_{2} \mathrm{O}(50 \mathrm{~mL}, 1 / 1$ mixture). (3) Crude 3 (around $1.82 \mathrm{mmol}$ ), $\mathrm{NH}_{2} \mathrm{OH} \cdot \mathrm{HCl}$ (2 equiv) in $\mathrm{HCOOH}(4.43 \mathrm{~mL})$. (4a) Crude 4 (around $1.55 \mathrm{mmol}$ ) in $1.25 \mathrm{M}$ $\mathrm{HCl}$ solution in $\mathrm{EtOH}$ (4 equiv). (4b) Crude $5 \cdot \mathrm{HCl}, \mathrm{NaOH}(1.5$ equiv). Overall yields of the isolated product.

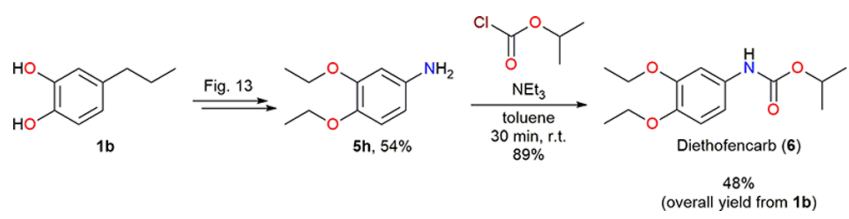

Figure 14. Preparation of diethofencarb (6) from $5 h$, as described by $\mathrm{Xu}$ et $\mathrm{al}^{68}$

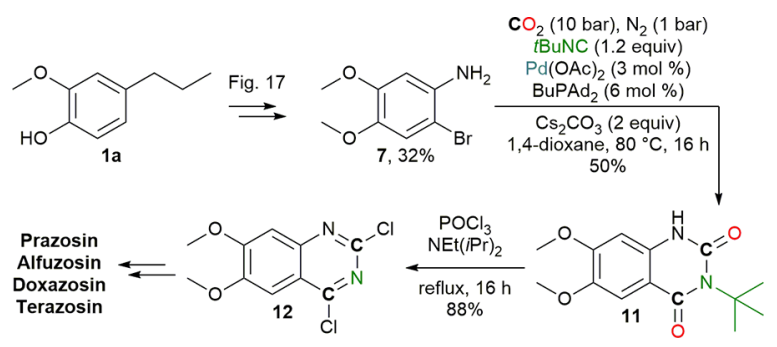

Figure 15. Preparation of APIs from $7 .^{39-47}$

out to be the solution as it gave the desired amide $\mathbf{1 0}$ with a satisfying yield of $86 \%$ (Figure 16, reaction D).

With identification of the right step for bromination, after the Beckmann rearrangement and preceding the alcoholysis, 7 was prepared from 1a following the order of steps presented in Figure 17. The sequence was again performed without any purification after each synthetic step, the crude mixture being each time directly used in a following transformation. Using the workup depicted in Figure 9, 7 was isolated with 32\% yield. This procedure to access 7 is a beautiful example where an aromatic amine can be more efficiently obtained and in an easier manner from a biorenewable feedstock than from fossil resources. Indeed, the yield of 7 from 1 a is already higher than the reported yield from $\mathbf{5 a},{ }^{40}$ which furthermore needs to be prepared from benzene as raw petrochemical material. This highlights the genuine potential of biorenewable resources to serve as surrogate aromatic starting material in fine chemicals applications. 


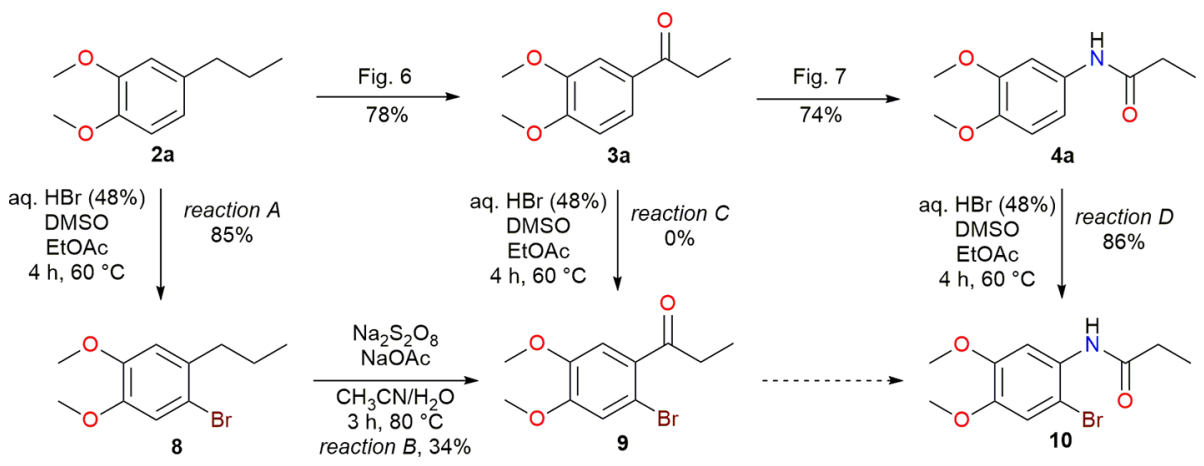

Figure 16. Possible strategies to access 2-bromo-3,4-dimethoxyaniline (7) from 2a. Reaction conditions: (A, C, and $\mathrm{D}) \mathrm{HBr}\left(48 \%\right.$ in $\left.\mathrm{H}_{2} \mathrm{O}\right)(1.1$ equiv), DMSO (1.1 equiv) in EtOAc $(5 \mathrm{~mL}), 4 \mathrm{~h}, 60^{\circ} \mathrm{C}$. (B) $\mathrm{Na}_{2} \mathrm{~S}_{2} \mathrm{O}_{8}$ (2 equiv), $\mathrm{NaOAc}$ (2 equiv) in $\mathrm{CH}_{3} \mathrm{CN} / \mathrm{H}_{2} \mathrm{O}(50 \mathrm{~mL}, 1 / 1 \mathrm{mixture}, 3 \mathrm{~h}, 80$ $\left.{ }^{\circ} \mathrm{C}\right)$.

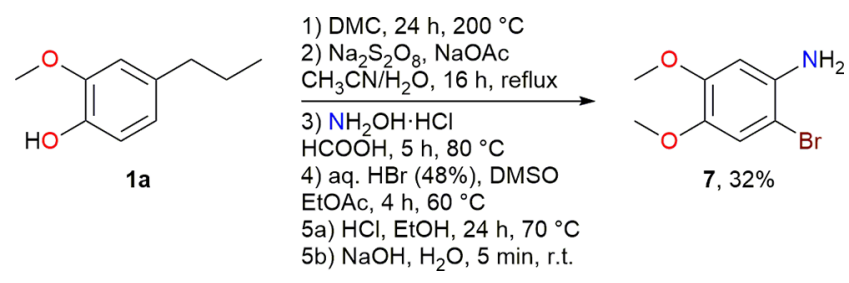

Figure 17. Preparation of 2-bromo-4,5-dimethoxyaniline (7) from 1a without intermediate isolation. Reaction conditions: (1) 1a $(2.80$ $\mathrm{mmol})$, DMC $(1.4 \mathrm{~mL}), \mathrm{K}_{2} \mathrm{CO}_{3}(1 \mathrm{~mol} \%)$. (2) Crude 2a (around $2.80 \mathrm{mmol}$ ), $\mathrm{Na}_{2} \mathrm{~S}_{2} \mathrm{O}_{8}$ (2.4 equiv), $\mathrm{NaOAc}$ (1.0 equiv) in $\mathrm{CH}_{3} \mathrm{CN} /$ $\mathrm{H}_{2} \mathrm{O}$ (50 mL, 1/1 mixture). (3) Crude 3a (around $2.08 \mathrm{mmol}$ ), $\mathrm{NH}_{2} \mathrm{OH} \cdot \mathrm{HCl}(2.0$ equiv) in $\mathrm{HCOOH}(3.2 \mathrm{~mL})$. (4) Crude $4 \mathrm{a}$ (around $1.56 \mathrm{mmol}$ ), DMSO (1.1 equiv), $\mathrm{HBr}\left(48 \%\right.$ in $\left.\mathrm{H}_{2} \mathrm{O}\right)(1.1$ equiv) in EtOAc $(15 \mathrm{~mL})$. (5a) Crude 10 (around $1.47 \mathrm{mmol}$ ) in $1.25 \mathrm{M} \mathrm{HCl}$ solution in $\mathrm{EtOH}$ (2.0 equiv). (5b) Crude $5 \cdot \mathrm{HCl}, \mathrm{NaOH}$ (1.5 equiv). Overall yields of the isolated product.

Evaluation of the Green Credentials for the Synthesis of 3,4-Dimethoxyaniline (5a) and 2-Bromo-4,5-dimethoxyaniline (7). In order to evaluate the "greenness" of the developed approach for the synthesis of dimethoxyanilines from biorenewable 4-propylguaicol, the different synthetic steps involved were evaluated using the CHEM21 Green Metrics Toolkit, developed by Clark et al. ${ }^{70}$ This assessment of the so-called "green metrics" is a relative concept considering both quantitative and qualitative parameters. Therefore, the same assessment of a classical synthesis route for the same compounds, obtained from literature data starting from a petrochemical resource, needs to be performed as well. This way, we were able to compare the newly developed routes with existing pathway(s) with respect to greenness. The literature pathways are also at the discovery level (First Pass in the Green Metrics) (vide infra). The selected classical pathways for 5a and 7 are shown in Figure 18 (black reactions). A detailed discussion of this approach can be found in the Supporting Information, together with an overview of the assumptions that were made for performing the calculations and general information about the Green Metrics Toolkit.

Quantitative Metrics. The following parameters were calculated for each individual step and the overall route: yield, $\mathrm{AE}$ (atom economy), RME (reaction mass efficiency), PMI (process mass intensity), PMI RRC (reactants, reagents, catalysts), PMI Rxn (reaction), and PMI WU (workup). When comparing the two approaches toward 3,4-dimethoxyaniline (5a), it can be seen that the step economy of the newly developed approach is higher since only four steps are required from 4-propylguaiacol (1a), while in the classical approach seven steps are necessary starting from benzene (Figure 18). For the synthesis of 2-bromo-4,5-dimethoxyaniline (7), both approaches require one additional step, the bromination, however at different places in the reaction sequence (Figure 18). In the classical synthesis, this additional step is performed on the reaction product 5a, while in the new approach this is done on $\mathrm{N}$-(3,4-dimethoxyphenyl)propanamide (4a), providing a significantly higher yield and, importantly, avoiding column chromatography for purification significantly impacting PMI. Important to note is that, in all steps of the new routes toward 5a and 7, no column chromatography is required. For the classical route this is also the case, except in the bromination step of 5a toward 7 (step 8) (Figure 18).

In Table 1, the cumulative overall values for the quantitative metrics for both the new and classical synthesis sequence toward 5a and 7 are reported. Values for the quantitative metrics for individual steps as well as the cumulative involving that specific step $n$ and all the preceding ones are presented in Figure S19 and Figure S20 for the classical synthesis route of 5a and 7, and in Figure S21 and Figure S22 for the new synthesis route of $5 \mathrm{a}$ and 7 , respectively.

When looking at the synthesis of 7 , the yield for the new approach is increased with $10 \%$ compared to the classical approach and the PMI Rxn reduced with $31 \%$ of the original value. The difference is smaller when reaction solvents (PMI RRC) are omitted (23\% reduction). The increases in RME and $\mathrm{AE}$ are the same (18\%). The graphical representation (see Supporting Information) of the metrics in the classical synthesis reveals that the bromination step (step 8) is the most material intensive step, while this is not the case for the new approach (step 4) (Figure S20d and Figure S22d). For mass-based metrics, the bottleneck in the new approach is the benzylic oxidation, which requires a high dilution of material in the $\mathrm{CH}_{3} \mathrm{CN} /$ water $(0.12 \mathrm{M})$ system (the impact of reaction solvent on PMI is revealed from the difference between PMI RRC and PMI Rxn; see Figure S21e,f and Figure S22e,f) and excess of oxidant (2.4 equiv, resulting in an RME for this specific step of $16 \%$, which is much lower than the AE (46\%); see Figure S21b,c and Figure S22b,c). Though the oxidation step requires a larger amount of solvent, cumulative overall PMI Rxn of the new approach for 7 is still lower than for the classical approach (225 versus 327$)$. It can be expected that further research regarding the optimization of solvent use in this specific step when moving toward pilot scale will make the new process overall even greener compared to existing methods. Solvent recycling on the other hand can also be an 


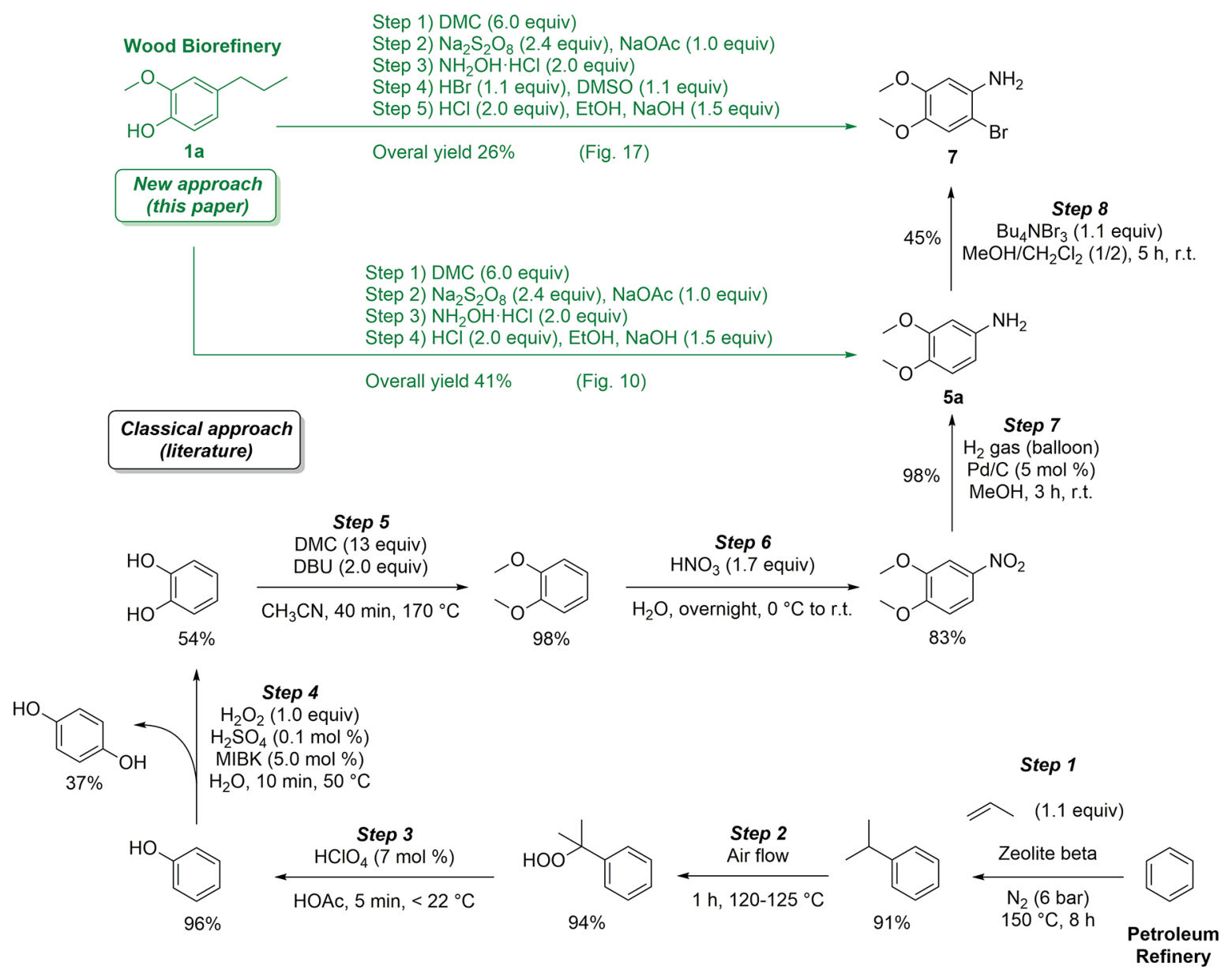

Figure 18. Synthesis of 3,4-dimethoxyaniline (5a) and 2-bromo-4,5-dimethoxyaniline (7) via a classical route (black) starting from benzene versus a new route (green) based on 4-propylguaiacol (1a). References regarding the literature procedure are given in the Supporting Information.

Table 1. Calculated Cumulative Overall Quantitative Metrics for the Synthesis of 3,4-Dimethoxyaniline (5a) and 2-Bromo-4,5dimethoxyaniline $(7)^{a}$

\begin{tabular}{|c|c|c|c|c|c|c|c|}
\hline route & yield (\%) & $\mathrm{AE}(\%)$ & RME (\%) & PMI $\left(g \cdot g^{-1}\right)$ & PMI RRC ${ }^{b}\left(g \cdot g^{-1}\right)$ & PMI $\operatorname{Rxn}^{c}\left(g \cdot g^{-1}\right)$ & PMI WU ${ }^{d}\left(\mathrm{~g} \cdot \mathrm{g}^{-1}\right)$ \\
\hline \multicolumn{8}{|c|}{ (1) 3,4-Dimethoxyaniline (5a) } \\
\hline classical & 35 & 45 & 10.30 & 423 & 12.7 & 194 & 228 \\
\hline new & 41 & 26 & 4.22 & 524 & 16.6 & 187 & 336 \\
\hline \multicolumn{8}{|c|}{ (2) 2-Bromo-4,5-dimethoxyaniline (7) } \\
\hline classical & 16 & 28 & 5.06 & $1394^{e}$ & 24.2 & 327 & $1067^{e}$ \\
\hline new & 26 & 34 & 6.15 & 673 & 18.7 & 225 & 449 \\
\hline
\end{tabular}

${ }^{a}$ For each compound, the obtained quantitative metrics are reported for both the classical and new route. ${ }^{b}$ RRC: Reactants, reagents, and catalysts. ${ }^{c}$ Rxn: Reaction. ${ }^{d}$ WU: Workup. ${ }^{e}$ These values decrease to 805 (PMI) and 478 (PMI WU) when column chromatography in step 8 is neglected in the calculation.

option when working on a larger scale. For the synthesis of $\mathbf{5 a}$ both classical and new approaches have a similar cumulative overall PMI Rxn (194 versus 187).

For the classical route toward 5a and 7, one needs to take into account that the first four steps, transforming benzene to catechol, are actually commercial processes and performed on a large scale and therefore fully optimized. On the contrary, our new routes entirely consist of steps for which at present only data on the discovery level are available. Cumulative overall PMI contains the PMI WU, which is not yet optimized in the discovery phase of development, and comparing cumulative overall PMIs for which one route partly contains steps performed on a larger scale is therefore not very instructive and has to be interpreted with care. However, for 7 the new route still reveals a much lower cumulative PMI. Even when the column chromatography in step 8 for the classical route is omitted from the calculations, the value is still much higher. "Neglecting" column chromatography of the workup decreases the cumulative overall PMI from 1394 to 805 which is still $17 \%$ higher than the new route (673). When comparing cumulative overall PMI for 5a, the classical route performs better, 423 versus 524, though the yield is slightly lower.

Qualitative Metrics. Next to the assessment of mass-based metrics, the Toolkit also focuses on some qualitative metrics for both routes, which are summarized in Table 2. A first improvement for the new route is the use of a biorenewable substrate, propylguaiacol (1a), fully in accordance with one of the 12 Principles of Green Chemistry. ${ }^{71}$ Compound 1a scores 
Table 2. Qualitative Appraisal of Solvent Use, Inherent Hazards of Used Chemicals, Catalyst or Reagent Use, Energy and Workup Methods for the Different Approaches for the Synthesis of 3,4-Dimethoxyaniline (5a) and 2-Bromo-4,5dimethoxyaniline (7)

\begin{tabular}{|c|c|c|c|c|c|c|c|c|c|c|c|c|}
\hline Step & Solvents & Flag & $\begin{array}{c}\text { Critical } \\
\text { elements }^{\mathrm{a}}\end{array}$ & Flag & $\begin{array}{c}\text { Health and } \\
\text { Safety }{ }^{\mathrm{a}}\end{array}$ & Flag & Reagent used & Flag & Energy & Flag & Work-up & Flag \\
\hline & \multicolumn{12}{|c|}{ Classical synthesis of 3,4-dimethoxyaniline (Steps 1-7) and 2-bromo-4,5-dimethoxyaniline (Steps 1-8) } \\
\hline 1 & No solvent & & - & & $\begin{array}{c}\text { Benzene: H372, } \\
\text { H340, H350 }\end{array}$ & & $\begin{array}{l}\text { No additional } \\
\text { reagent }\end{array}$ & & $150^{\circ} \mathrm{C}$ & & Distillation & \\
\hline 2 & No solvent & & - & & Cumene: H411 & & $\begin{array}{l}\text { No additional } \\
\text { reagent }\end{array}$ & & $\begin{array}{c}118- \\
126^{\circ} \mathrm{C}\end{array}$ & & Distillation & \\
\hline 3 & HOAc & & - & & - & & Catalyst & & $<22^{\circ} \mathrm{C}$ & & Filtration & \\
\hline 4 & $\mathrm{H}_{2} \mathrm{O}$ & & S & & - & & Catalyst & & $50{ }^{\circ} \mathrm{C}$ & & Distillation & \\
\hline 5 & $\mathrm{CH}_{3} \mathrm{CN}$ & & - & & DBU: H311 & & Stoichiometric & & $170^{\circ} \mathrm{C}$ & & Extraction & \\
\hline 6 & $\mathrm{Et}_{2} \mathrm{O}$ & & - & & $\begin{array}{c}\mathrm{Et}_{2} \mathrm{O}: \mathrm{H} 224 \\
\mathrm{HNO}_{3}: \mathrm{H} 331\end{array}$ & & Catalyst & & $0{ }^{\circ} \mathrm{C}$ to r.t. & & $\begin{array}{l}\text { Filtration, } \\
\text { Washing }\end{array}$ & \\
\hline 7 & $\mathrm{MeOH}$ & & $\mathrm{Pd}$ & & MeOH: H370 & & Catalyst & & r.t. & & Filtration & \\
\hline 8 & $\mathrm{CH}_{2} \mathrm{Cl}_{2}, \mathrm{Et}_{2} \mathrm{O}$ & & - & & $\begin{array}{c}\text { MeOH: H370 } \\
\text { Heptane: H410 }\end{array}$ & & $\begin{array}{c}\text { No additional } \\
\text { reagent }\end{array}$ & & r.t. & & Column chrom. & \\
\hline \multicolumn{13}{|c|}{ New synthesis of 3,4-dimethoxyaniline } \\
\hline 1 & DMC, EtOAc & & - & & 4-PG: H311 & & Catalyst & & $200^{\circ} \mathrm{C}$ & & Filtration & \\
\hline 2 & $\mathrm{CH}_{3} \mathrm{CN}$ & & S & & $\mathrm{Na}_{2} \mathrm{~S}_{2} \mathrm{O}_{8}: \mathrm{H} 371$ & & Stoichiometric & & Reflux & & Extraction & \\
\hline 3 & $\begin{array}{l}\mathrm{HCOOH}, \\
\text { MTBE }\end{array}$ & & - & & $\begin{array}{c}\mathrm{NH}_{2} \mathrm{OH} \cdot \mathrm{HCl}: \\
\mathrm{H} 400\end{array}$ & & $\begin{array}{l}\text { No additional } \\
\text { reagent }\end{array}$ & & $80^{\circ} \mathrm{C}$ & & Extraction & \\
\hline 4 & $\begin{array}{c}\mathrm{EtOH}, \mathrm{H}_{2} \mathrm{O} \\
\text { EtOAc }\end{array}$ & & - & & - & & $\begin{array}{c}\text { No additional } \\
\text { reagent }\end{array}$ & & $70^{\circ} \mathrm{C}$ & & Extraction & \\
\hline \multicolumn{13}{|c|}{ New synthesis of 2-bromo-4,5-dimethoxyaniline } \\
\hline 1 & DMC, EtOAc & & - & & 4-PG: H311 & & Catalyst & & $200^{\circ} \mathrm{C}$ & & Filtration & \\
\hline 2 & $\mathrm{CH}_{3} \mathrm{CN}$ & & S & & $\mathrm{Na}_{2} \mathrm{~S}_{2} \mathrm{O}_{8}: \mathrm{H} 371$ & & Stoichiometric & & Reflux & & Extraction & \\
\hline 3 & $\begin{array}{l}\mathrm{HCOOH}, \\
\text { МTBE }\end{array}$ & & - & & $\begin{array}{c}\mathrm{NH}_{2} \mathrm{OH} \cdot \mathrm{HCl}: \\
\mathrm{H} 400\end{array}$ & & $\begin{array}{l}\text { No additional } \\
\text { reagent }\end{array}$ & & $80^{\circ} \mathrm{C}$ & & Extraction & \\
\hline 4 & EtOAc & & S & & - & & Stoichiometric & & $60^{\circ} \mathrm{C}$ & & Extraction & \\
\hline 5 & $\begin{array}{c}\mathrm{EtOH}, \mathrm{H}_{2} \mathrm{O} \\
\text { EtOAc }\end{array}$ & & - & & - & & $\begin{array}{c}\text { No additional } \\
\text { reagent }\end{array}$ & & $70{ }^{\circ} \mathrm{C}$ & & Extraction & \\
\hline
\end{tabular}

${ }^{a}$ When a yellow or red flag is not applicable, this column is left blank.

better for "Health and Safety" than benzene and cumene as substrate, since it is only considered as "toxic in contact with skin" (H311), which gives it a yellow flag, while the involvement of benzene and cumene brings serious implications (benzene, "Causes damage to organs through prolonged or repeated exposure" (H372), "May cause genetic defects" (H340), "May cause cancer" (H350), 3 red flags; cumene, "Toxic to aquatic life with long-lasting effects" (H410), one red flag). Furthermore, looking at other chemicals used, in the new method only one red flag is obtained for Health and Safety on the basis of $\mathrm{NH}_{2} \mathrm{OH} \cdot \mathrm{HCl}$ ("Very toxic to aquatic life", $\mathrm{H} 400$ ) involvement, though it is widely used in industry, while the classical method requires the use of $\mathrm{MeOH}$ and heptane (this last solvent was not used in the reaction but as column chromatography solvent for the workup), both leading to an additional red flag. Also for the yellow flags in the Health and Safety category, the new approach scores better ( 1 yellow flag for $\mathrm{Na}_{2} \mathrm{~S}_{2} \mathrm{O}_{8}$ ) than the classical ( 3 yellow flags for $\mathrm{DBU}, \mathrm{Et}_{2} \mathrm{O}$, and $\mathrm{HNO}_{3}$ ). Considering the most recent CHEM21 Solvent Selection Guide, ${ }^{72}$ we specifically avoided the use of "hazardous" and "highly hazardous" solvents in both reaction and workup, such as $\mathrm{Et}_{2} \mathrm{O}$ or $\mathrm{CH}_{2} \mathrm{Cl}_{2}$, which are both present in the classical approach. Therefore, for the new approach only yellow flags are obtained for $\mathrm{CH}_{3} \mathrm{CN}, \mathrm{HCOOH}$, and MTBE, in contrast with the classical method which scores 3 red flags (for
$\mathrm{CH}_{2} \mathrm{Cl}_{2}$ and 2 times for $\mathrm{Et}_{2} \mathrm{O}$ ) and 2 yellow flags (HOAc and $\mathrm{CH}_{3} \mathrm{CN}$ ). Also for critical elements, only 1 yellow flag was obtained in the new method, while for the classical method 1 yellow and 1 red flag are obtained. The yellow flags (estimated supply remaining for 50-500 years) are due to the use of sulfur $\left(\mathrm{Na}_{2} \mathrm{~S}_{2} \mathrm{O}_{8}\right.$ and DMSO in the new method and $\mathrm{H}_{2} \mathrm{SO}_{4}$ in the classical) and the red flag (estimated supply remaining for less than 50 years) because of the use of palladium. In all other steps, elements were used of which the remaining supply is estimated more than 500 years, leading to green flags.

When looking at chemical requirements of the new method, it can be seen that for the benzylic oxidation $(\mathrm{NaOAc})$ in the formation of both products and for the additional bromination step (DMSO) in the specific synthesis of 7 , the use of a stoichiometric reagent was required (yellow flag), which was for the literature approach only the case in one reaction step (DBU in step 5). None of the reported reactions, both in the classical and in the new routes, made use of reagents in excess. Concerning energy requirement, two steps in the new route receive a red flag because reflux was found crucial in the benzylic oxidation of 4-propylveratrole (2a) and $200{ }^{\circ} \mathrm{C}$ was required for achieving high yield and selectivity in the methylation of 4-propylguaiacol (1a) using dimethyl carbonate, which is an inherent property of this reactant. Also in the classical route, 2 red flags were obtained for energy 
requirement since both the alkylation of benzene and the methylation of catechol require high temperature. One needs to realize that this is a very basic analysis and does not reflect the final energy use which is also not possible at the discovery level as the reaction times are not minimized. This analysis therefore just highlights specific steps with high energy use. Considering the number of steps for the new routes toward 5a and 7 are significantly smaller, it can moreover be expected that energy use on larger scale will be smaller.

Concerning workup, the classical method involves unavoidable column chromatography for one of the reactions, namely, the bromination of 5a (step 8) (Figure 18), leading to a red flag, while none of the steps in the new approach required this purification method. Although we repeated this literature bromination reaction, we could only slightly increase the yield and application of alternative workups hitherto completely failed. On the other hand, all other reaction steps in the classical approach are worked-up via simple techniques, such as filtration or distillation (green flags) and extraction (yellow flag). These techniques were used in all steps of the new approaches toward $\mathbf{5 a}$ and 7 .

\section{CONCLUSIONS}

We have developed a methodology to transform important lignin-based monomers such as 4-propylguaiacol (1a) and 4propylcatechol (1b) into valuable aromatic amines and esters. The process is based on an $O$-alkylation of $\mathbf{1 a}$ and $\mathbf{1} \mathbf{b}$ followed by a benzylic oxidation, Beckmann rearrangement, and amide alcoholysis to access the target 3,4-dialkoxyanilines. In the amide alcoholysis, alkyl propionates are formed as byproducts which are valuable products used as solvents and flavors in industry. The aromatic amines were prepared from a biorenewable arene resource as a direct alternative to their classical preparation from petrochemical benzene, avoiding the use of nitric acid to introduce the nitrogen atom. Several of the bio-based 3,4-dialkoxyanilines obtained are drop-in chemicals as they are described in the synthesis of anticancer drugs (Prazosin, Alfuzosin, Doxazosin, Terazosin, Gefitinib, and Erlotinib) agrochemicals (Diethofencarb) and dyes.

Based on the first pass metrics assessment, we can conclude that the new approaches for the synthesis of dialkoxyanilines 5a and 7 are more step efficient. Moreover, they perform respectively similar or better in comparison to literature routes with respect to PMI Rxn. In addition, our procedures make use of cheap and industrially accepted chemicals and start from a compound obtained via a biorefinery, 4-propylguaiacol (1a). Concerning "Health and Safety" of substrate, reactants, and reagents, only one red flag for $\mathrm{NH}_{2} \mathrm{OH} \cdot \mathrm{HCl}$ is obtained, while the classical got 3 or 5 for respectively 5 a and 7. The use of hazardous and highly hazardous solvents is avoided. Moreover, all reactions could be performed regio- and chemoselectively (e.g., in the Beckman rearrangement only one product was formed). The metrics allowed identification aspects in the reactions which should be part of further research when moving toward scaleup. For example, the benzylic oxidation requires a higher dilution $\left(\mathrm{CH}_{3} \mathrm{CN} /\right.$ water mixture as solvent). Considering our developed approach is only in a discovery stage, workup cannot be objectively compared with literature routes. Nevertheless, the cumulative PMI for 7 was already lower. The workup of our new routes only involved recommended solvents and simple techniques such as extraction and filtration.
All experimental procedures, together with characterization of the obtained compounds (PDF)

\section{AUTHOR INFORMATION}

\section{Corresponding Author}

*E-mail: Bert.Maes@UAntwerpen.be.

ORCID

Jeroen Bomon: 0000-0003-3029-302X

Bert Sels: 0000-0001-9657-1710

Bert U. W. Maes: 0000-0003-0431-7606

\section{Notes}

The authors declare no competing financial interest.

\section{ACKNOWLEDGMENTS}

We acknowledge the financial support from VLAIO/Catalisti (ARBOREF), UAntwerpen (BOF), the Hercules Foundation, the Research Foundation Flanders (FWO) (WOG and BioFact Excellence of Science project Grant No. 30902231), and the BIO-HArT project which is established by a contribution of the European Interreg $\mathrm{V}$ Flanders-The Netherlands program that stimulates innovation, sustainable energy, a healthy environment, and the labor market by means of cross-border projects. We thank Dr. Manuel Jörres for initial experiments in this research project.

\section{REFERENCES}

(1) Kahl, T.; Schröder, K.-W.; Lawrence, F. R.; Marshall, W. J.; Höke, H.; Jäckh, R., Aniline. Ullmann's Encyclopedia of Industrial Chemistry; Wiley-VCH: 2011; DOI: 10.1002/ 14356007.a02 303.pub2.

(2) Vogt, P. F.; Gerulis, J. J., Aromatic amines. In Ullmann's Encyclopedia of Industrial Chemistry; Wiley-VCH: 2011; DOI: 10.1002/14356007.a02 037.

(3) Westerhaus, F. A.; Jagadeesh, R. V.; Wienhöfer, G.; Pohl, M.-M.; Radnik, J.; Surkus, A.-E.; Rabeah, J.; Junge, K.; Junge, H.; Nielsen, M.; Brückner, A.; Beller, M. Heterogenized cobalt oxide catalysts for nitroarene reduction by pyrolysis of molecularly defined complexes. Nat. Chem. 2013, 5 (6), 537-543.

(4) Jagadeesh, R. V.; Surkus, A.-E.; Junge, H.; Pohl, M.-M.; Radnik, J.; Rabeah, J.; Huan, H.; Schünemann, V.; Brückner, A.; Beller, M. Nanoscale $\mathrm{Fe}_{2} \mathrm{O}_{3}$-Based Catalysts for Selective Hydrogenation of Nitroarenes to Anilines. Science 2013, 342 (6162), 1073-1076.

(5) Wei, H.; Liu, X.; Wang, A.; Zhang, L.; Qiao, B.; Yang, X.; Huang, Y.; Miao, S.; Liu, J.; Zhang, T. $\mathrm{FeO}_{\mathrm{x}}$-supported platinum single-atom and pseudo-single-atom catalysts for chemoselective hydrogenation of functionalized nitroarenes. Nat. Commun. 2014, 5, 5634.

(6) Baeten, M.; Maes, B. U. W. Carbon-Nitrogen Bond Formation Through Cross-Dehydrogenative Coupling Reactions. In Advances in Organometallic Chemistry; Pérez, P. J., Ed.; Elsevier: 2017; Vol. 67, Chapter Five, pp 401-481, DOI DOI: 10.1016/bs.adomc.2017.04.003.

(7) Froidevaux, V.; Negrell, C.; Caillol, S.; Pascault, J. P.; Boutevin, B. Biobased Amines: From Synthesis to Polymers; Present and Future. Chem. Rev. 2016, 116 (22), 14181-14224.

(8) Jadhav, A. S.; Vernekar, S. P.; Maldar, N. N. Synthesis and characterization of new aromatic sulfone ether polyamides containing pendant pentadecyl groups. Polym. Int. 1993, 32 (1), 5-11.

(9) Mhaske, S. B.; Bhingarkar, R. V.; Sabne, M. B.; Mercier, R.; Vernekar, S. P. Synthesis and characterization of end-capped 
polyimides and their gas permeability properties. J. Appl. Polym. Sci. 2000, 77 (3), 627-635.

(10) Attanasi, O. A.; Berretta, S.; Fiani, C.; Filippone, P.; Mele, G.; Saladino, R. Synthesis and reactions of nitro derivatives of hydrogenated cardanol. Tetrahedron 2006, 62 (25), 6113-6120.

(11) Sadavarte, N. V.; Halhalli, M. R.; Avadhani, C. V.; Wadgaonkar, P. P. Synthesis and characterization of new polyimides containing pendent pentadecyl chains. Eur. Polym. J. 2009, 45 (2), 582-589.

(12) Calvo-Flores, F. G.; Dobado, J. A. Lignin as Renewable Raw Material. ChemSusChem 2010, 3 (11), 1227-1235.

(13) Rinaldi, R.; Jastrzebski, R.; Clough, M. T.; Ralph, J.; Kennema, M.; Bruijnincx, P. C. A.; Weckhuysen, B. M. Paving the Way for Lignin Valorisation: Recent Advances in Bioengineering, Biorefining and Catalysis. Angew. Chem., Int. Ed. 2016, 55 (29), 8164-8215.

(14) Liu, W.-J.; Jiang, H.; Yu, H.-Q. Thermochemical conversion of lignin to functional materials: a review and future directions. Green Chem. 2015, 17 (11), 4888-4907.

(15) Li, C.; Zhao, X.; Wang, A.; Huber, G. W.; Zhang, T. Catalytic Transformation of Lignin for the Production of Chemicals and Fuels. Chem. Rev. 2015, 115 (21), 11559-624.

(16) Zakzeski, J.; Bruijnincx, P. C. A.; Jongerius, A. L.; Weckhuysen, B. M. The Catalytic Valorization of Lignin for the Production of Renewable Chemicals. Chem. Rev. (Washington, DC, U. S.) 2010, 110 (6), 3552-3599.

(17) Pandey, M. P.; Kim, C. S. Lignin Depolymerization and Conversion: A Review of Thermochemical Methods. Chem. Eng. Technol. 2011, 34 (1), 29-41.

(18) Xu, C.; Arancon, R. A. D.; Labidi, J.; Luque, R. Lignin depolymerisation strategies: towards valuable chemicals and fuels. Chem. Soc. Rev. 2014, 43 (22), 7485-7500.

(19) Chan, J. M. W.; Bauer, S.; Sorek, H.; Sreekumar, S.; Wang, K.; Toste, F. D. Studies on the Vanadium-Catalyzed Nonoxidative Depolymerization of Miscanthus giganteus-Derived Lignin. ACS Catal. 2013, 3 (6), 1369-1377.

(20) Gao, F.; Webb, J. D.; Sorek, H.; Wemmer, D. E.; Hartwig, J. F. Fragmentation of Lignin Samples with Commercial Pd/C under Ambient Pressure of Hydrogen. ACS Catal. 2016, 6, 7385-7392.

(21) Zeng, J.; Yoo, C. G.; Wang, F.; Pan, X.; Vermerris, W.; Tong, Z. Biomimetic Fenton-Catalyzed Lignin Depolymerization to HighValue Aromatics and Dicarboxylic Acids. ChemSusChem 2015, 8 (5), 861-871.

(22) Rahimi, A.; Ulbrich, A.; Coon, J. J.; Stahl, S. S. Formic-acidinduced depolymerization of oxidized lignin to aromatics. Nature 2014, 515 (7526), 249-252.

(23) Deuss, P. J.; Lahive, C. W.; Lancefield, C. S.; Westwood, N. J.; Kamer, P. C.; Barta, K.; de Vries, J. G. Metal Triflates for the Production of Aromatics from Lignin. ChemSusChem 2016, 9 (20), 2974-2981.

(24) Lahive, C. W.; Deuss, P. J.; Lancefield, C. S.; Sun, Z.; Cordes, D. B.; Young, C. M.; Tran, F.; Slawin, A. M.; de Vries, J. G.; Kamer, P. C.; Westwood, N. J.; Barta, K. Advanced Model Compounds for Understanding Acid-Catalyzed Lignin Depolymerization: Identification of Renewable Aromatics and a Lignin-Derived Solvent. J. Am. Chem. Soc. 2016, 138 (28), 8900-8911.

(25) Song, Q.; Wang, F.; Cai, J.; Wang, Y.; Zhang, J.; Yu, W.; Xu, J. Lignin depolymerization (LDP) in alcohol over nickel-based catalysts via a fragmentation-hydrogenolysis process. Energy Environ. Sci. 2013, 6 (3), 994-1007.

(26) Van den Bosch, S.; Schutyser, W.; Koelewijn, S. F.; Renders, T.; Courtin, C. M.; Sels, B. F. Tuning the lignin oil $\mathrm{OH}$-content with $\mathrm{Ru}$ and Pd catalysts during lignin hydrogenolysis on birch wood. Chem. Commun. (Cambridge, U. K.) 2015, 51 (67), 13158-13161.

(27) Renders, T.; Van den Bosch, S.; Koelewijn, S. F.; Schutyser, W.; Sels, B. F. Lignin-first biomass fractionation: the advent of active stabilisation strategies. Energy Environ. Sci. 2017, 10 (7), 1551-1557.

(28) Galkin, M. V.; Smit, A. T.; Subbotina, E.; Artemenko, K. A.; Bergquist, J.; Huijgen, W. J.; Samec, J. S. Hydrogen-free catalytic fractionation of woody biomass. ChemSusChem 2016, 9 (23), 32803287.
(29) Schutyser, W.; Van den Bosch, S.; Dijkmans, J.; Turner, S.; Meledina, M.; Van Tendeloo, G.; Debecker, D. P.; Sels, B. F. Selective nickel-catalyzed conversion of model and lignin-derived phenolic compounds to cyclohexanone-based polymer building blocks. ChemSusChem 2015, 8 (10), 1805-1818.

(30) Feghali, E.; Carrot, G.; Thuery, P.; Genre, C.; Cantat, T. Convergent reductive depolymerization of wood lignin to isolated phenol derivatives by metal-free catalytic hydrosilylation. Energy Environ. Sci. 2015, 8 (9), 2734-2743.

(31) Lancefield, C. S.; Ojo, O. S.; Tran, F.; Westwood, N. J. Isolation of Functionalized Phenolic Monomers through Selective Oxidation and C-O Bond Cleavage of the $\beta$-O-4 Linkages in Lignin. Angew. Chem., Int. Ed. 2015, 54 (1), 258-262.

(32) Zhao, S.; Abu-Omar, M. M. Biobased Epoxy Nanocomposites Derived from Lignin-Based Monomers. Biomacromolecules 2015, 16 (7), 2025-2031.

(33) Zhao, S.; Abu-Omar, M. M. Renewable Epoxy Networks Derived from Lignin-Based Monomers: Effect of Cross-Linking Density. ACS Sustainable Chem. Eng. 2016, 4 (11), 6082-6089.

(34) Koelewijn, S. F.; Van den Bosch, S.; Renders, T.; Schutyser, W.; Lagrain, B.; Smet, M.; Thomas, J.; Dehaen, W.; Van Puyvelde, P.; Witters, H.; Sels, B. F. Sustainable bisphenols from renewable softwood lignin feedstock for polycarbonates and cyanate ester resins. Green Chem. 2017, 19 (11), 2561-2570.

(35) Koelewijn, S. F.; Cooreman, C.; Renders, T.; Andecochea Saiz, C.; Van den Bosch, S.; Schutyser, W.; De Leger, W.; Smet, M.; Van Puyvelde, P.; Witters, H.; Van der Bruggen, B.; Sels, B. F. Promising bulk production of a potentially benign bisphenol A replacement from a hardwood lignin platform. Green Chem. 2018, 20 (5), 1050-1058.

(36) Schutyser, W.; Van den Bosch, S.; Dijkmans, J.; Turner, S.; Meledina, M.; Van Tendeloo, G.; Debecker, D. P.; Sels, B. F. Selective Nickel-Catalyzed Conversion of Model and Lignin-Derived Phenolic Compounds to Cyclohexanone-Based Polymer Building Blocks. ChemSusChem 2015, 8 (10), 1805-1818.

(37) Xu, L.; Yao, Q.; Zhang, Y.; Fu, Y. Integrated Production of Aromatic Amines and N-Doped Carbon from Lignin via ex Situ Catalytic Fast Pyrolysis in the Presence of Ammonia over Zeolites. ACS Sustainable Chem. Eng. 2017, 5 (4), 2960-2969.

(38) Marzaro, G.; Guiotto, A.; Pastorini, G.; Chilin, A. A novel approach to quinazolin-4(3H)-one via quinazoline oxidation: an improved synthesis of 4-anilinoquinazolines. Tetrahedron 2010, 66 (4), 962-968.

(39) Mampuys, P.; Neumann, H.; Sergeyev, S.; Orru, R. V. A.; Jiao, H.; Spannenberg, A.; Maes, B. U. W.; Beller, M. Combining Isocyanides with Carbon Dioxide in Palladium-Catalyzed Heterocycle Synthesis: N3-Substituted Quinazoline-2,4(1H,3H)-diones via a Three-Component Reaction. ACS Catal. 2017, 7 (8), 5549-5556.

(40) Lopez-Tapia, F.; Walker, K. A. M.; Brotherton-Pleiss, C.; Caroon, J.; Nitzan, D.; Lowrie, L.; Gleason, S.; Zhao, S.-H.; Berger, J.; Cockayne, D.; Phippard, D.; Suttmann, R.; Fitch, W. L.; Bourdet, D.; Rege, P.; Huang, X.; Broadbent, S.; Dvorak, C.; Zhu, J.; Wagner, P.; Padilla, F.; Loe, B.; Jahangir, A.; Alker, A. Novel Series of Dihydropyridinone P2 $\times 7$ Receptor Antagonists. J. Med. Chem. 2015, 58 (21), 8413-8426.

(41) Silvani, A.; Lesma, G.; Crippa, S.; Vece, V. Multicomponent access to novel dihydroimidazo $\left[1^{\prime}, 5^{\prime}: 1,2\right]$ pyrido $[3,4-b]$ indol-2-ium salts and indoles by means of Ugi/Bischler-Napieralski/heterocyclization two step strategy. Tetrahedron 2014, 70 (26), 3994-4001.

(42) Ladd, C. L.; Sustac Roman, D.; Charette, A. B. SilverPromoted, Palladium-Catalyzed Direct Arylation of Cyclopropanes: Facile Access to Spiro 3,3'-Cyclopropyl Oxindoles. Org. Lett. 2013, 15 (6), 1350-1353.

(43) Baudoin, O.; Claveau, F.; Thoret, S.; Herrbach, A.; Guénard, D.; Guéritte, F. Synthesis and biological evaluation of a-Ring biarylcarbamate analogues of rhazinilam. Bioorg. Med. Chem. 2002, 10 (11), 3395-3400.

(44) Andrus, M. B.; Mettath, S. N.; Song, C. A Modified Synthesis of Iodoazidoaryl Prazosin. J. Org. Chem. 2002, 67 (23), 8284-8286. 
(45) Zunszain, P. A.; Federico, C.; Sechi, M.; Al-Damluji, S.; Ganellin, C. R. Search for the pharmacophore in prazosin for Transport-P. Bioorg. Med. Chem. 2005, 13 (11), 3681-3689.

(46) Kleemann, A.; Engel, J.; Kutscher, B.; Reichert, D. Pharmaceutical Substances; Thieme, 2001.

(47) Xu, P.; Wang, F.; Wei, T.-Q.; Yin, L.; Wang, S.-Y.; Ji, S.-J. Palladium-Catalyzed Incorporation of Two C1 Building Blocks: The Reaction of Atmospheric $\mathrm{CO}_{2}$ and Isocyanides with 2-Iodoanilines Leading to the Synthesis of Quinazoline-2,4(1H,3H)-diones. Org. Lett. 2017, 19 (17), 4484-4487.

(48) Bulk chemical prices for Indian import/export of batches $>2$ tons based on data found on Zauba.com.

(49) Unger, T. A., Diethofencarb. Pesticide Synthesis Handbook; William Andrew, 1996.

(50) Ritz, J.; Fuchs, H.; Kieczka, H.; Moran, W. C. Caprolactam. Ullmann's Encyclopedia of Industrial Chemistry; Wiley-VCH: 2011; DOI: 10.1002/14356007.a05_031.pub2.

(51) Samel, U.-R.; Kohler, W.; Gamer, A. O.; Keuser, U. Propionic acid and derivatives. Ullmann's Encyclopedia of Industrial Chemistry; Wiley-VCH: 2011; DOI: 10.1002/14356007.a22 223.pub2.

(52) Tundo, P.; Selva, M. The Chemistry of Dimethyl Carbonate. Acc. Chem. Res. 2002, 35 (9), 706-716.

(53) Selva, M.; Perosa, A. Green chemistry metrics: a comparative evaluation of dimethyl carbonate, methyl iodide, dimethyl sulfate and methanol as methylating agents. Green Chem. 2008, 10 (4), 457-464.

(54) Arico, F.; Tundo, P. Dimethyl carbonate: a modern green reagent and solvent. Russ. Chem. Rev. 2010, 79, 479-489.

(55) Sterckx, H.; Morel, B.; Maes, B. U. Recent advances in catalytic aerobic oxidation of $\mathrm{C}\left(\mathrm{sp}^{3}\right)-\mathrm{H}$ bonds. Angew. Chem., Int. Ed. 2018, DOI: $10.1002 /$ anie.201804946.

(56) Revathi, L.; Ravindar, L.; Fang, W.-Y.; Rakesh, K. P.; Qin, H.-L. Visible Light-Induced $\mathrm{C}-\mathrm{H}$ Bond Functionalization: A Critical Review. Adv. Synth. Catal. 2018, 360 (24), 4652-4698.

(57) White, M. C.; Zhao, J. Aliphatic C-H Oxidations for Late-Stage Functionalization. J. Am. Chem. Soc. 2018, 140 (43), 13988-14009.

(58) Joshi, B. P.; Sharma, A.; Sinha, A. K. Microwave- and ultrasound-assisted semisynthesis of natural methoxylated propiophenones from isomeric mixture of phenylpropenes in minutes. Can. J. Chem. 2005, 83 (10), 1826-1832.

(59) Pandey, G.; Pal, S.; Laha, R. Direct benzylic C-H activation for C-O bond formation by photoredox catalysis. Angew. Chem., Int. Ed. 2013, 52 (19), 5146-5149.

(60) Klenk, H.; Götz, P. H.; Siegmeier, R; Mayr, W. Peroxy compounds, organic. Ullmann's Encyclopedia of Industrial Chemistry; Wiley-VCH: 2011; DOI: 10.1002/14356007.a19 199.

(61) Nakanishi, M.; Bolm, C. Iron-Catalyzed Benzylic Oxidation with Aqueous tert-Butyl Hydroperoxide. Adv. Synth. Catal. 2007, 349 (6), 861-864.

(62) Harald, J.; Leininger, S.; Lehmann, T.; Jacobi, S.; Gutewort, S. Peroxy compounds, inorganic. Ullmann's Encyclopedia of Industrial Chemistry; Wiley-VCH: 2011; DOI: $10.1002 /$ 14356007.a19_177.pub2.

(63) More, $\bar{N}$. Y.; Jeganmohan, M. Aerobic Dehydrogenative $\alpha$ Diarylation of Benzyl Ketones with Aromatics through CarbonCarbon Bond Cleavage. Org. Lett. 2014, 16 (3), 804-807.

(64) Sathyamoorthi, S.; Du Bois, J. Copper-Catalyzed Oxidative Cyclization of Carboxylic Acids. Org. Lett. 2016, 18 (24), 6308-6311.

(65) Lee, M.; Sanford, M. S. Remote $\mathrm{C}\left(\mathrm{sp}^{3}\right)-\mathrm{H}$ Oxygenation of Protonated Aliphatic Amines with Potassium Persulfate. Org. Lett. 2017, 19 (3), 572-575.

(66) Smith, J. Preservatives. In Food Additives Data Book, 2nd ed.; Smith, J., Hong-Shum, L., Eds.; Wiley, 2011; DOI: 10.1002/ 9781444397741.ch11.

(67) EFSA ANS Panel (EFSA Panel on Food Additives and Nutrient Sources added to Food). Safety of the extension of use of sodium propionate (E 281) as a food additive. EFSA J. 2016, 14 (8), e4546.

(68) Xu, S.; Sun, L.; Fei, X.; Sun, M.; Wang, H.; Wang, S.; Li, Y.; Wang, W.; Yang, Q.; Li, Y. Study on synthesis of fungicides diethofencarb. Yingyong Huagong 2010, 39 (1), 30-32.
(69) Song, S.; Sun, X.; Li, X.; Yuan, Y.; Jiao, N. Efficient and Practical Oxidative Bromination and Iodination of Arenes and Heteroarenes with DMSO and Hydrogen Halide: A Mild Protocol for Late-Stage Functionalization. Org. Lett. 2015, 17 (12), 28862889.

(70) McElroy, C. R.; Constantinou, A.; Jones, L. C.; Summerton, L.; Clark, J. H. Towards a holistic approach to metrics for the 21st century pharmaceutical industry. Green Chem. 2015, 17 (5), 31113121.

(71) Anastas, P. T.; Warner, J. C. Green Chemistry: Theory and Practice; Oxford University Press, 1998.

(72) Prat, D.; Wells, A.; Hayler, J.; Sneddon, H.; McElroy, C. R.; Abou-Shehada, S.; Dunn, P. J. CHEM21 selection guide of classicaland less classical-solvents. Green Chem. 2016, 18 (1), 288-296. 